\title{
Measuring the sustainable urbanization potential of cities in Northeast China
}

\author{
LIU Shiwei ${ }^{1},{ }^{*}$ ZHANG Pingyu ${ }^{1}$, WANG Zheye ${ }^{2}$, LIU Wenxin ${ }^{1}$, TAN Juntao ${ }^{1}$ \\ 1. Northeast Institute of Geography and Agroecology, CAS, Changchun 130102, China; \\ 2. Department of Geography, Kent State University, Kent, OH 44240, USA
}

\begin{abstract}
Sustainable urbanization is not only an important research topic in the field of urbanization, but also the development direction of new-type urbanization. In this paper, we construct an index system to evaluate sustainable urbanization potential with the entropy method. Results show that potential values of sustainable urbanization in most cities are not high. Cities with higher sustainable urbanization potential values are mainly located in the central part of Northeast China. Environmental potential of sustainable urbanization is the main contributor to sustainable urbanization potential in Northeast China. There is no absolute relationship between city size and potential value, large city does not always mean greater potential. Correlation analysis shows that urbanization rate cannot reflect the sustainable urbanization potential of a region. Population urbanization is not the ultimate goal of sustainable urbanization. Unilateral pursue urbanization rate cannot improve the potential of sustainable urbanization. Towards sustainable urbanization, governments in Northeast China should revitalize local economy, pay more attention to the rural areas and develop low-carbon economy or ecological economy. Finally, this paper highlights the importance of choosing more integrated methodology or new models for measuring sustainable urbanization potential in view of the shortcomings of one method.
\end{abstract}

Keywords: sustainable urbanization potential; entropy method; Northeast China

\section{Introduction}

Humanity today is experiencing a massive urbanization. According to United Nations' latest research, more than half of the world's population living in urban areas today and percentage of urban population will continue to grow and will rise to $67 \%$ by 2050 (United Nations, 2012). Urbanization brings many benefits, such as economies of scale, richer market structures, jobs, recreation, health and education improvement (Bloom et al., 2008). However, rapid urbanization also brings many serious problems, such as irreversible land-cover

Received: 2015-07-14 Accepted: 2015-12-10

Foundation: National Natural Science Foundation of China, No.41571152, No.41301111, No.41201159, No. 71541021; Science and Technology Association Decision-making Advisory Project of Jilin Province, No.KX2015002

Author: Liu Shiwei (1986-), PhD and Assistant Professor, specialized in regional development and agricultural geography. E-mail: liushiwei@iga.ac.cn

*Corresponding author: Zhang Pingyu (1966-), PhD and Professor, E-mail: zhangpy@iga.ac.cn 
changes, biodiversity loss, environment degradation, congestion, widening gap between rich and poor (Grimm et al., 2008; Bloom et al., 2008). These problems pose barriers to the achievement of sustainable development. Consequently, humanity today needs to find a way combat these problems. As an important component of sustainable development, sustainable urbanization was put forward by the UN-Habitat/DFID in the "Sustainable Urbanization Achieving Agenda 21" report, and they emphasized that "Without sustainable urbanization, sustainable development cannot be achieved" (UN-Habitat/DFID, 2002). Since then sustainable urbanization has been gradually accepted and recognized by governments and academic circles. Many countries, such as United States, China and Rwanda have held international conference on sustainable urbanization. Sustainable urbanization has therefore become a hot topic among governments, public, and scholars.

Northeast China used to be the largest old industrial base in China. Since the central government implemented the strategy of revitalizing the old industrial base of Northeast China in 2003, urbanization rate has increased steadily in this region. In 2013, the proportion of the urban population in Northeast China reached 59.35\%. However, its traditional urbanization is not sustainable. Regional urbanization rate still grows slowly (Zhang, 2013). The industrial structure of this region is dominated by heavy industry, leading to a lack of endogenous motivation in urbanization development (Zang et al., 2013). Resource-based cities are still in transition. Contradiction of urban labor supply and demand is outstanding which lead to a high unemployment rate (Li et al., 2010). Big cities are not growing at a smart way, land urbanization growth rate is faster than that of the population urbanization (Sun et al., 2013). More and more rural people migrate to urban areas, but they do not have the same rights as the urban citizen (Long et al., 2009). Urbanization quality is poor and infrastructure is severely deficient in some cities (Liu et al., 2007). As an important aspect of promoting sustainable development, sustainable urbanization will be very helpful to the revitalization of Northeast China. In this paper, we take cities in Northeast China as a case study area and evaluate sustainable urbanization potential of this region. The result may enrich researches on sustainable urbanization and provide some suggestions for Northeast China.

The remainder of the paper is organized as follows: the next section introduces the literature review of sustainable urbanization. Section 3 briefly describes the case study area. Section 4 introduces the data source, indicator system and methodology. Section 5 reports the empirical results, and the final section reaches certain conclusions.

\section{Literature review}

\subsection{Sustainable urbanization}

Sustainable urbanization is the development of the sustainable development theory. Since the UN-Habitat/DFID (2002) released the sustainable urbanization report, sustainable urbanization gradually attracted scholars' attention. Pivo (1996) believed that sustainable urbanization should follow six basic principles: compactness, completeness, conservation, comfort, coordination, and collaboration. Drakakis-Smith and Dixon (1997) introduced a synthesized framework to understand the connotation of sustainable urbanization from the perspectives of demographic, social, economic, political, and environmental performances. UN-Habitat/DFID (2002) concluded that "Sustainable urbanization" is a dynamic and multi- 
dimensional process covering economic, social, environmental and political-institutional sustainability. Roy (2009) contended that sustainable urbanization is urbanization process that fulfills the principles of sustainable development.

In recent years, remote sensing technology, cellular automata model, SLEUTH model and other advanced methods have been used to monitor the impact of urbanization on environment (Dewan and Yamaguchi, 2009; Irwin et al., 2009; Jantz et al., 2003). As to the development strategy, Holden (2004) suggested four models of sustainable urban form, namely "urban sprawl", "the green city", "large (monolithic) compact city" and "decentralized concentration", with the model of decentralized concentration more conducive to sustainability. Verma et al. (2013) believed high-speed rail can promote the growth of mega-cities, and strengthen the links between medium-sized cities and small cities. Enserink and Koppenjan (2007) suggested that meaningful public participation is very helpful in sustainable urbanization policy making. Zhu and Simarmata (2015) indicated that for governance sustainable urbanization the key to ending of spatial dichotomy of social classes in Indonesia lies in the collection action.

Domestic research on sustainable urbanization synchronized with the international. Especially since the 18th National Congress of the Communist Party of China, sustainable urbanization has become a hot topic of government departments and scholars. Niu (2009) depicted the target of sustainable urbanization is to realize population, resource and environment coordinated with each other and promote the unity of city and countryside. Shen and Zhou (2014) provided a method to examining the effectiveness of indicators for guiding sustainable urbanization. Zhu (2014) constructed an index system to evaluate the level of sustainable urbanization in Heilongjiang. Shen et al. (2015) introduced a hybrid EntropyMcKinsey Matrix method for evaluating sustainable urbanization. Zhang (2015) proposed a roadmap for effective acquisition and sharing of sustainable urbanization experiences to support the decision making processes.

\subsection{Sustainable urbanization potential}

Potential is the inherent strength or ability that did not play out. Currently potential researches are focusing on the potential for regional sustainable development, enterprise development potential as well as the tourism potential, and study on sustainable urbanization potential or the potential of urbanization is still relatively insufficient. In research content, foreign scholars focused on the potential of the individual elements of advancing urbanization, and mainly about the economic potential (Ma et al., 2009). Such as Romer (1990), Arrow (1962) and Florida (1995) considered the factors of production (such as capital and labor) are factors that determine the economic potential of the region.

Chinese scholars emphasized integrated urban potential factors. He (1992) constructed an urbanization potential factor index system from economy, social and ecological aspects. Liu and Sun (2007) established an index system by population, the number of students in the school, urban industrial output, foreign investment, and per capita savings for studying the potential of rural urbanization in Heilongjiang Province. For the sustainable urbanization strategy, Fang and Ma (2013) suggested China should adjust industrial structure, intensive land use and narrow the urban-rural gap. Chen et al. (2015) studied the relationship between urbanization and economic development, and emphasized that it is important to optimize the 
spatial organization. Wang et al. (2011) pointed out that future development of Northeast China should focus on urban agglomeration organization structure. While Yi et al. (2015) emphasized that the prerequisite for new urbanization in Northeast China is to promote the coordinated development of industrialization, urbanization, agricultural modernization and informationization.

The above discussions show that scholars have introduced various methods and ways to guide the practice of sustainable urbanization. However, few studies have addressed sustainable urbanization potential which denotes the capability of a region developing in a sustainable way in future. To reach sustainable urbanization, it is important to evaluate the sustainable urbanization potential of a region, and the result will be very helpful to policy makers to develop scientific policies.

\section{Study area}

The study area, located in Northeast China, includes 36 prefecture-level cities, bordered to the north and west by Russia and Mongolia and to the south-east by North Korea (Figure 1). It used to be the largest industrial base in China, and developed after the founding of New China owing to its abundant natural resources, unique development history and geopolitical relations with the Soviet Union. It was the national center of heavy industry and served as the engine of national reconstruction in the 1950s. In 2013, gross regional product has reached 5444.2 billion yuan in this region, accounting for $9.6 \%$ of the country's total. Population has reached 109.8 million and about $59.35 \%$ of the population living in urban areas.

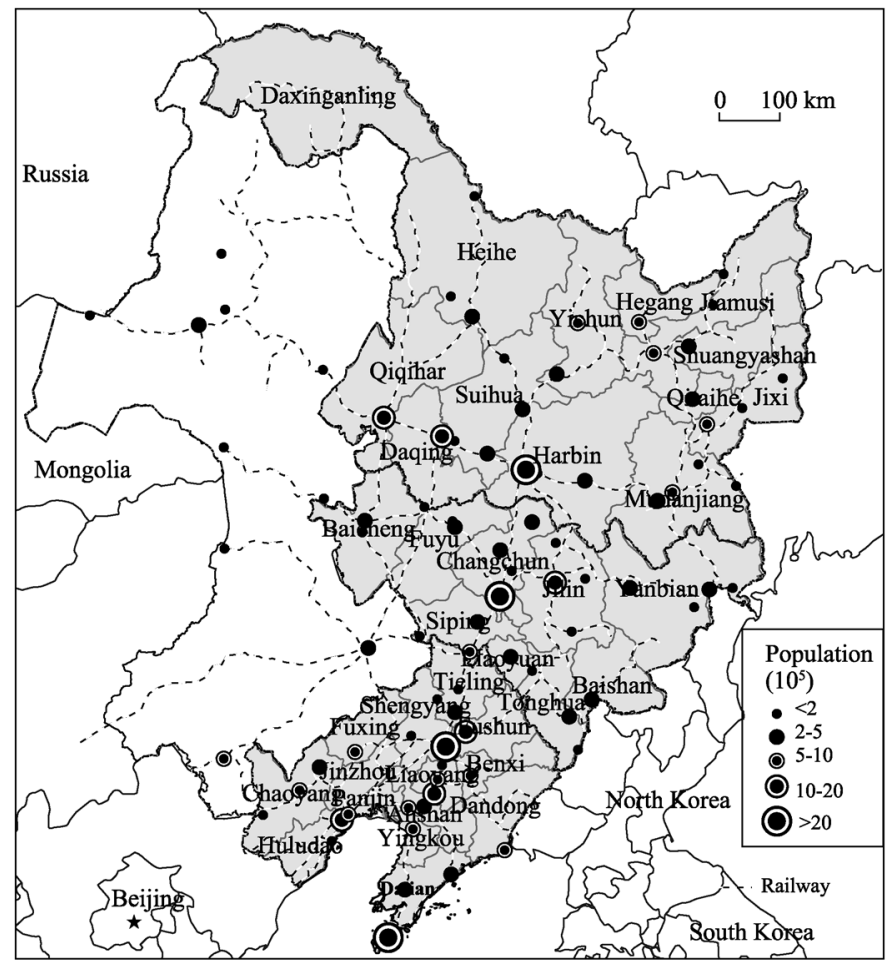

Figure 1 The study area of Northeast China 


\section{Material and methods}

\subsection{Data source}

The data used in this paper are from various publications of Liaoning Statistical Yearbook 2006-2011, Jilin Statistical Yearbook 2006-2011, Heilongjiang Statistical Yearbook 2006-2011, China City Statistical Yearbook 2006-2011, China Statistical Yearbook for Regional Economy 2006-2011, and China County Statistical Yearbook 2011.

\subsection{The index system}

UN Habitat/DFID (2002) suggested that sustainable urbanization is a dynamic, multi-dimensional process including economic, social and environmental sustainability. Therefore, sustainable urbanization potential is also a multi-dimensional concept including economic, social and environmental potential. Sustainable urbanization potential is the capability of a region's development in a sustainable urbanization way in future. Compared with the urbanization quality, sustainable urbanization potential emphasize more the dynamic of urbanization, competitive ability, innovation ability, coping ability and sustainable development ability of a region.

Economic potential of sustainable urbanization describes the ability of promoting economic sustainability in the process of urbanization. Urbanization is the result of push-pull force of cities and rural areas. In order to ensure the continued urbanization progress, cities must develop urban economy to create more jobs and also rural areas should develop rural economy to release more agricultural labors. The urbanization progress cannot be made at the expense of the interests of any party, otherwise it will cause many serious urban-rural problems which may not conducive to social stability. Therefore, the economic potential of sustainable urbanization includes three parts: urban economic development capability, rural economic development capability and balance ability (equity between urban and rural development).

Social potential of sustainable urbanization describes the ability of promoting social sustainability in the process of urbanization. Government is a very important factor to promote social sustainability. Function of the government in the urbanization process includes: providing enough infrastructure and public services, offering basic social security and promoting the development of science and cultural undertakings. Therefore, social potential of sustainable urbanization can be described by government's social security ability, public infrastructure supply ability and culture and technology support ability.

Environmental potential of sustainable urbanization denotes the ability of promoting environmental sustainability in the process of urbanization. The environmental potential of sustainable urbanization not only depends on regional ecological carrying capacity, but also regional resource conservation ability and environmental protection ability.

Based on the studies of Meine and Zhang (2005), Lu et al. (2003), Niu (2012), and Shen et al. $(2012,2014,2015)$, we constructed a hierarchical system of indicators to understand sustainable urbanization potential from economic potential of sustainable urbanization, social potential of sustainable urbanization and environmental potential of sustainable urbanization (Table 1), the detailed information about ideas and choice of indicators see Liu (2014). 
A list of all indicators is given in Appendix. Each component consists of several subcomponents and indicators in levels IV and V.

Table 1 Indicator system for measuring sustainable urbanization potential

\begin{tabular}{|c|c|c|c|c|}
\hline $\begin{array}{l}\text { System index } \\
\text { (Level I) }\end{array}$ & Subsystem index (Level II) & $\begin{array}{l}\text { Components index } \\
\text { (Level III) }\end{array}$ & $\begin{array}{l}\text { Subcomponents index } \\
\text { (Level IV) }\end{array}$ & $\begin{array}{l}\text { Indicators } \\
\text { (Level V) }\end{array}$ \\
\hline \multirow{22}{*}{$\begin{array}{c}\text { Sustainable } \\
\text { urbanization } \\
\text { potential }\end{array}$} & \multirow{9}{*}{$\begin{array}{l}\text { Economic potential } \\
\text { of sustainable } \\
\text { urbanization }\end{array}$} & \multirow{4}{*}{$\begin{array}{l}\text { Urban economic } \\
\text { development } \\
\text { capability }\end{array}$} & Economic growth capability; & 4 \\
\hline & & & Elements gathering capability; & 3 \\
\hline & & & Global capability; & 3 \\
\hline & & & Innovation capability. & 2 \\
\hline & & \multirow{3}{*}{$\begin{array}{l}\text { Rural economic } \\
\text { development } \\
\text { capability }\end{array}$} & Agricultural modernization level; & 3 \\
\hline & & & Rural industrialization level. & 3 \\
\hline & & & Fiscal balance; & 2 \\
\hline & & \multirow[t]{2}{*}{ Balance ability } & Investment balance; & 2 \\
\hline & & & Urban-rural integration level. & 2 \\
\hline & \multirow{7}{*}{$\begin{array}{l}\text { Social potential } \\
\text { of sustainable } \\
\text { urbanization }\end{array}$} & \multirow{2}{*}{$\begin{array}{l}\text { Government's social } \\
\text { security ability }\end{array}$} & Financial security; & 3 \\
\hline & & & Personal security. & 2 \\
\hline & & \multirow{3}{*}{$\begin{array}{l}\text { Public infrastructure } \\
\text { supply ability }\end{array}$} & Medical services supply; & 2 \\
\hline & & & Transportation supply capability; & 3 \\
\hline & & & Water and electricity supply capability. & 2 \\
\hline & & \multirow{2}{*}{$\begin{array}{l}\text { Culture and technology } \\
\text { support ability }\end{array}$} & Technology supportive; & 2 \\
\hline & & & Culture supportive. & 2 \\
\hline & \multirow{6}{*}{$\begin{array}{l}\text { Environmental } \\
\text { potential of } \\
\text { sustainable } \\
\text { urbanization }\end{array}$} & \multirow{2}{*}{$\begin{array}{l}\text { Ecological } \\
\text { carrying capacity }\end{array}$} & Water resources carrying capacity; & 1 \\
\hline & & & Land carrying capacity. & 1 \\
\hline & & \multirow{2}{*}{$\begin{array}{l}\text { Environmental } \\
\text { protection ability }\end{array}$} & Greening capability; & 2 \\
\hline & & & Waste treatment capability. & 5 \\
\hline & & \multirow{2}{*}{$\begin{array}{l}\text { Resource conservation } \\
\text { ability }\end{array}$} & Resource efficient use capability; & 2 \\
\hline & & & Waste utilization capability. & 2 \\
\hline
\end{tabular}

\subsection{Weighting method}

During the process of evaluating the composite index, it is necessary to calculate relative weights for each indicator. In practice, weights can be either subjective or objective. Since the measurement of sustainable urbanization potential involves many aspects of a city, it is difficult to decide the actual importance or weight of each indicator by subjective judgment. In this paper, we choose an objective method to calculate the weights of indicators. Entropy method is an objective weighting method which could eliminate the subjective favor of valuator (Chen et al., 2010). It was used in the social sciences on a wide scale to measure the uncertainty of system. In general, the value of information entropy is lower, the system is more unbalanced, the difference is greater, and the change is sooner; so, the weight of the index is higher. Conversely, the weight of the index is lower. The main calculation steps of entropy method are as follows:

(1) Data standardizing: when the index value is greater, the system is more advantageous. The positive calculation method was used. 


$$
X_{\mathrm{ij}}^{\prime}=\left(X_{i j}-\min \left\{X_{j}\right\}\right) /\left(\max \left\{X_{j}\right\}-\min \left\{X_{j}\right\}\right)
$$

Conversely, the negative calculation method was used.

$$
X_{\mathrm{ij}}^{\prime}=\left(\max \left\{X_{j}\right\}\right)-X_{i j} /\left(\max \left\{X_{j}\right\}-\min \left\{X_{j}\right\}\right)
$$

(2) Calculating the proportion of index $j$ in city $i$ :

$$
Y_{i j}=X_{i j}^{\prime} / \sum_{i=1}^{m} X_{i j}^{\prime}
$$

(3) Calculating the information entropy of index:

$$
e_{j}=-k \sum_{i=1}^{m}\left(Y_{i j} \times \ln Y_{i j}\right), k=1 / \ln m, 0 \leqslant e_{j} \leqslant 1
$$

(4) Calculating the redundancy of information entropy:

(5) Calculating the weighting of index:

$$
d_{j}=1-e_{j}
$$

$$
w_{j}=d_{j} / \sum_{j=1}^{n} d_{j}
$$

(6) Calculating the value of single index evaluation:

$$
S_{i j}=w_{j} \times X_{i j}^{\prime}
$$

(7) Calculating the value of comprehensive evaluation in city $i$ :

$$
S_{i}=\sum_{j=1}^{n} S_{i j}
$$

where $X$ represents the value of index $j$ in city $i . \operatorname{Min}\left\{X_{j}\right\}$ and $\max \left\{X_{j}\right\}$ express respectively the minimum and the maximum of index $j$. In addition, $m$ is the number of city, and $n$ is the number of index.

\subsection{Integrated assessment}

Since the potential of sustainable urbanization includes economic potential of sustainable urbanization, social potential of sustainable urbanization and environmental potential of sustainable urbanization, and each layer of the system is equally important. This paper adopts the above method to calculate the entropy of each system layer, the weights listed in Appendix. The final score for city $i$ is:

$$
P_{i}=S_{i E}+S_{i S}+S_{i E n}
$$

where $P_{i}$ is the integrated potential value of city $i, S_{i E}$ is the economic potential value of city $i, S_{i S}$ is the social potential value of city $i, S_{i E n}$ is the environmental potential value of city $i$.

\section{Results and discussion}

\subsection{Economic potential of sustainable urbanization}

Economic potential of sustainable urbanization varies among different cities (Figure 2). Dalian got the highest score (0.8070), followed by Shenyang (0.5331), Harbin (0.3518), and Changchun (0.3464). Qitaihe, Hegang, and Yichun got lower scores, and the highest score of Dalian is 9.6 times higher than the lowest score of Yichun. Results of the components index 

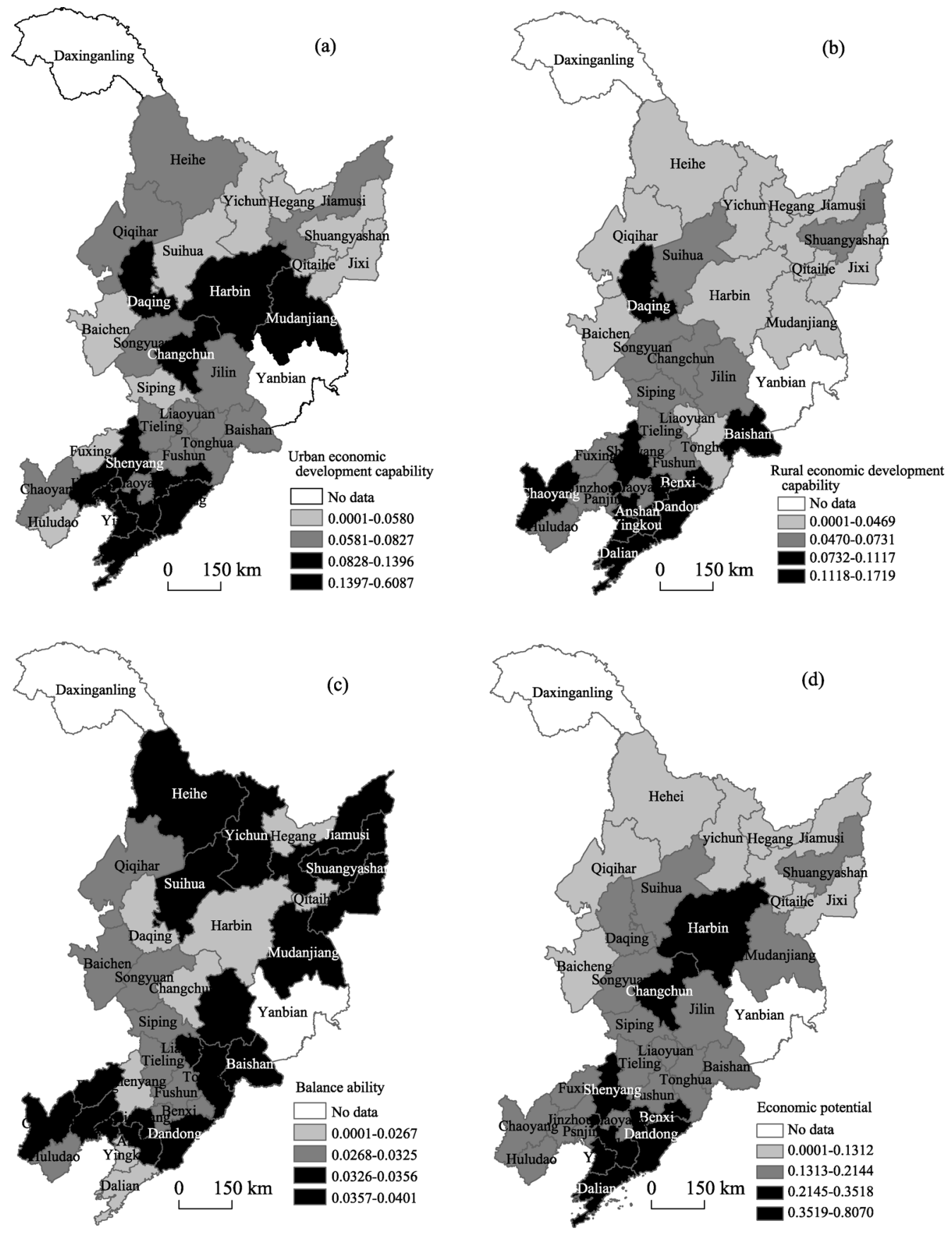

Figure 2 Economic potential of sustainable urbanization in Northeast China

shows that the most competitive city is Dalian, followed by Shenyang, Changchun and Harbin. Economic potentialities of these cities are strong, which have a strong attraction to the floating population. Because these cities can offer more job opportunities, higher labor remuneration, good education resources and other aspects that the small and medium-sized cities cannot provide. This result is consistent with the trend of population movement in Northeast China (Liang et al., 2013). Along with the development of urbanization, the mas- 
sive floating populations move to the large cities and the mega-cities. Globalization capability and regional innovation capability are two main factors influencing the urban economic development capability. Dalian, Yingkou, Shenyang, and Dandong have a strong rural development capability. The level of agricultural modernization in these cities was relatively high, which was $0.1015,0.1332$ and 0.0497 , respectively. The values of urban and rural balance ability index present a different scenario. Cities with higher urban economic development capability, such as Harbin, Shenyang and Changchun got lower scores in urban and rural balance ability index. Take Changchun for example, per capita fixed assets investment in municipal district is 5 times of non-municipal district, per capita expenditure in municipal district is 2.7 times of non-municipal district and annual per capita disposable income of urban households is 2.7 times of rural households. Therefore, eliminating gap betwwen urban and rural will be an important issue to be resolved in Northeast China.

Proportion of components index in prefecture-level cities is shown in Figure 3. For most of cities, urban economic development capability is the main contributor of the economic potential of sustainable urbanization value (Figure 3). This result is consistent with Gan et al. (2015) study, who found the main power source of urbanization in Northeast China is economic growth. Toward sustainable urbanization, the priority target of Northeast China is to revitalize local economy, promote economy transformation in resources cities and old urban industrial areas, optimize industrial structure, foster new industries, and establish a diversified modern industrial system (Wang et al., 2008). The second is to promote regional economic cooperation, increase investment for technology and education, and enhance regional innovation capacity. The ultimate goal is to form a healthy urban economy that can generate work opportunities for the growing urban population and promote the urbanization progress. Economic potential of sustainable urbanization is the resultant force of urban economic

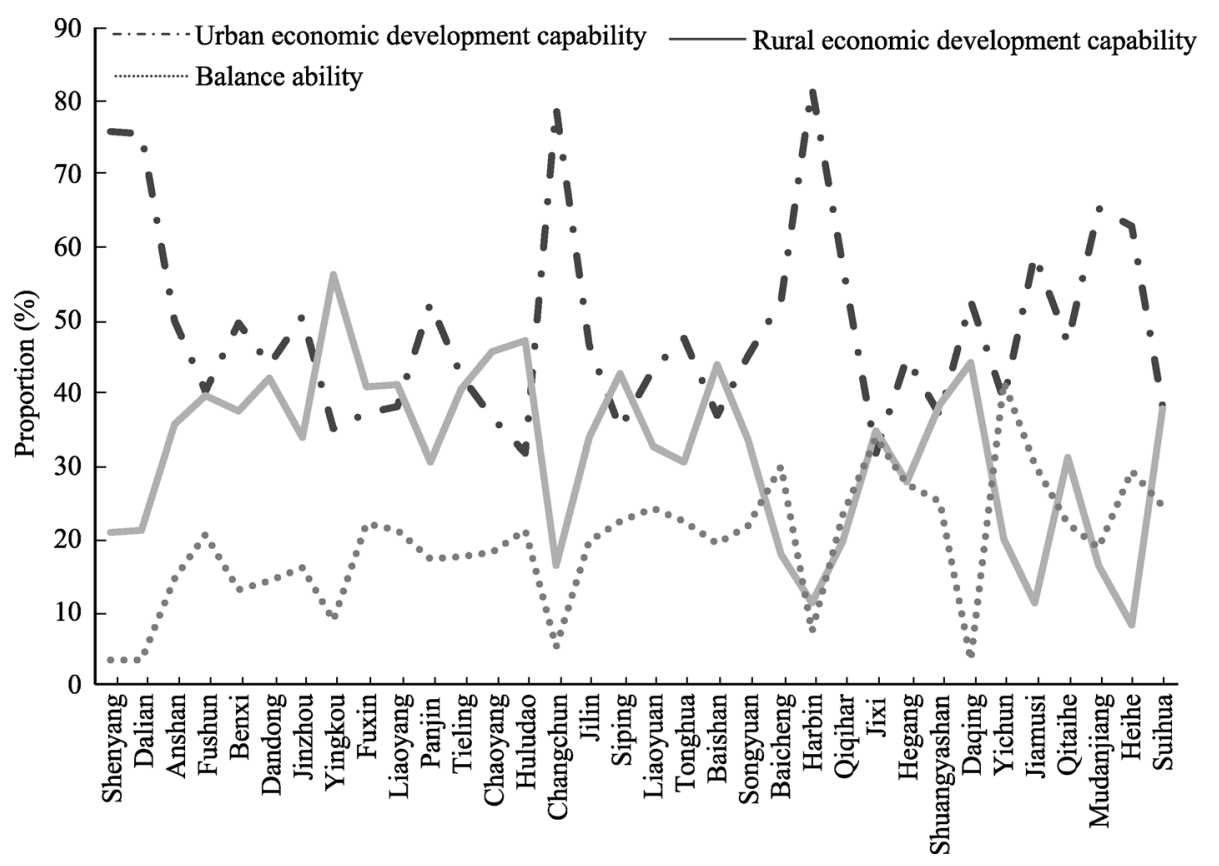

Figure 3 Proportion of components index in economic potential of sustainable urbanization in Northeast China 
development capability, rural development capability, and the urban and rural balance ability. Governments should take advantage of agricultural resources in Northeast China, support rural development, and promote urban and rural balance in future.

\subsection{Social potential of sustainable urbanization}

Social potential of sustainable urbanization in Northeast China is shown in Figure 4. Among
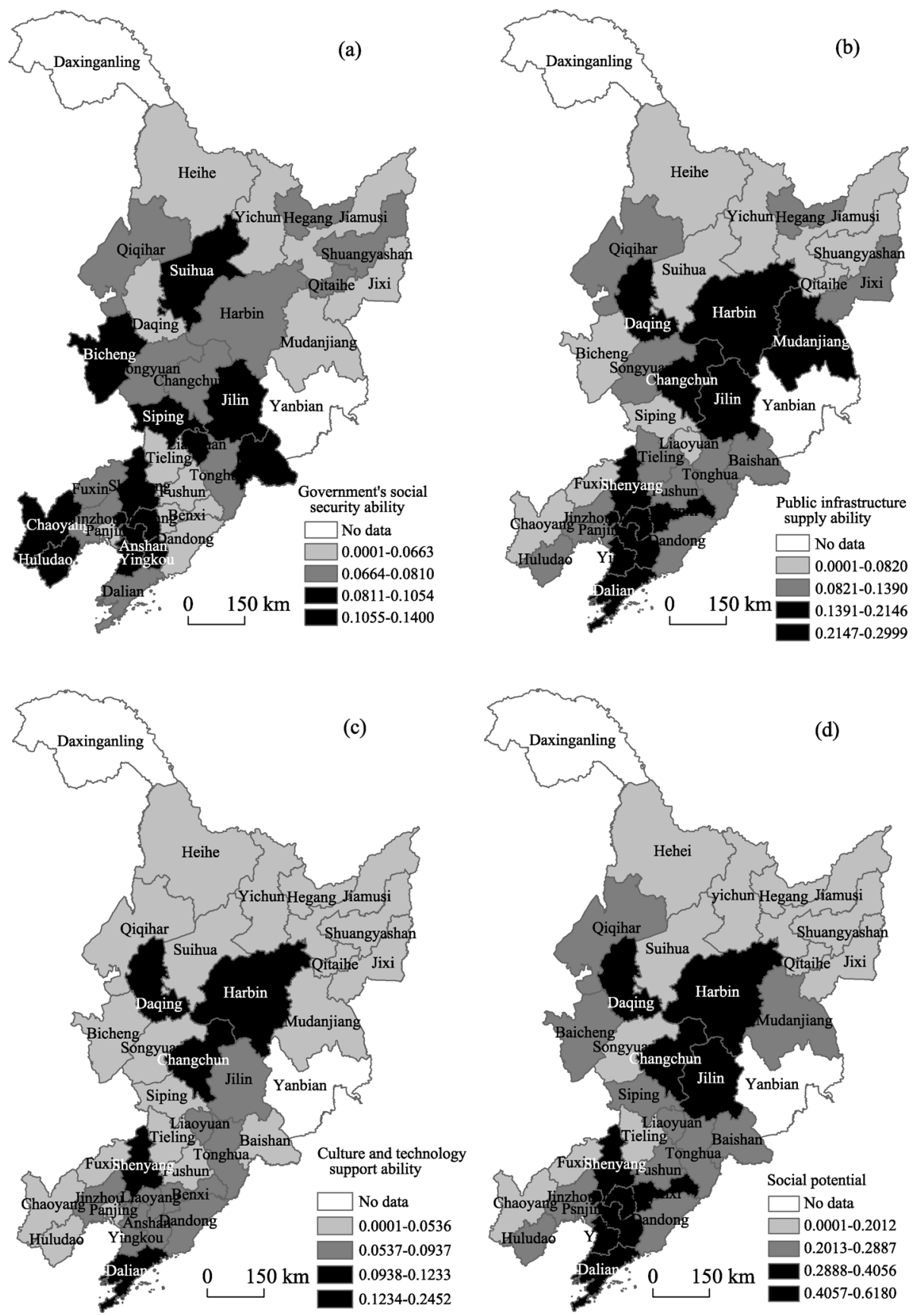

Figure 4 Social potential of sustainable urbanization in Northeast China 
the 36 cities at the prefecture level, Dalian (0.6180), Shenyang (0.5646), Daqing (0.5200), Anshan (0.4059), Changchun (0.3740) and Harbin (0.3567) are the top six cities of social potential value in Northeast China. On the other hand, Qitaihe, Yichun, and Suihua are the bottom three cities. The maximum is 4.87 times of the minimum score. Results of the components index shows that Baicheng gets the highest score in the government's social security ability, followed by Siping and Anshan. These cities spend more financial expenditures on education, social security and employment and health care than other cities. Such as Baicheng, the registered urban unemployment rate is $2.2 \%$ and proportion of the population under the minimum living guarantee line only accounts for $2.92 \%$, which are lower than those of many other cities. Dalian got the highest score in the public infrastructure supply capability, followed by Daqing and Shenyang. These cities with good geographic conditions and stronger economic strength can spend more money on transportation and medical services. Water supply capacity in Anshan, Benxi and Mudanjiang is relatively strong, so these cities obtained relatively high public infrastructure service capability scores. Figure 5 shows the proportion of components index for social potential of sustainable urbanization. Most of the prefecture-level cities in Liaoning Province have high public infrastructure supply ability, hence the major contributors of their social potential of sustainable urbanization scores. While results of social potential of sustainable urbanization in Heilongjiang and Jilin are mainly affected by government's social security ability and public infrastructure supply ability, contributions of culture and technology support ability of the two provinces are relatively low.

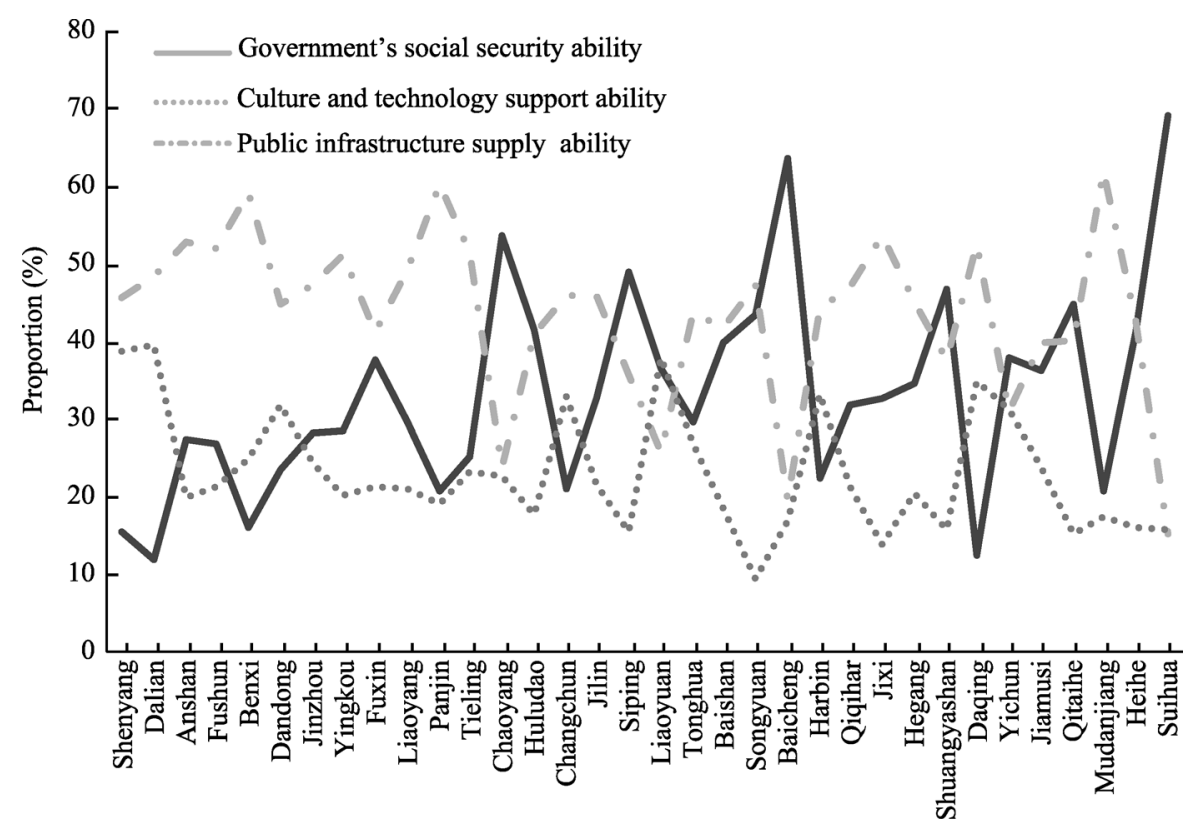

Figure 5 Proportion of components index in social potential of sustainable urbanization in Northeast China

Unemployment in cities dependent on old heavy industries was particularly severe, and the lack of effective training and other labor market mechanisms suited to the market economy made the problems worse (Ding, 2005). So the priority target of improving social sustainability in the urbanization progress is to strengthen social security systems and pro- 
mote local employment by means of providing reliable infrastructure and services, such as energy supply, transport, communications and water supply, and making sure each person have equal access to equal quality urban services.

\subsection{Environmental potential of sustainable urbanization}

Cities with higher scores of environmental potential are concentrated in the central part of Northeast China (Figure 6). Tonghua (0.6429) ranked first in environmental potential, followed by Daqing (0.5682), Changchun (0.5502), Fushun (0.5288), Tieling (0.5261) and
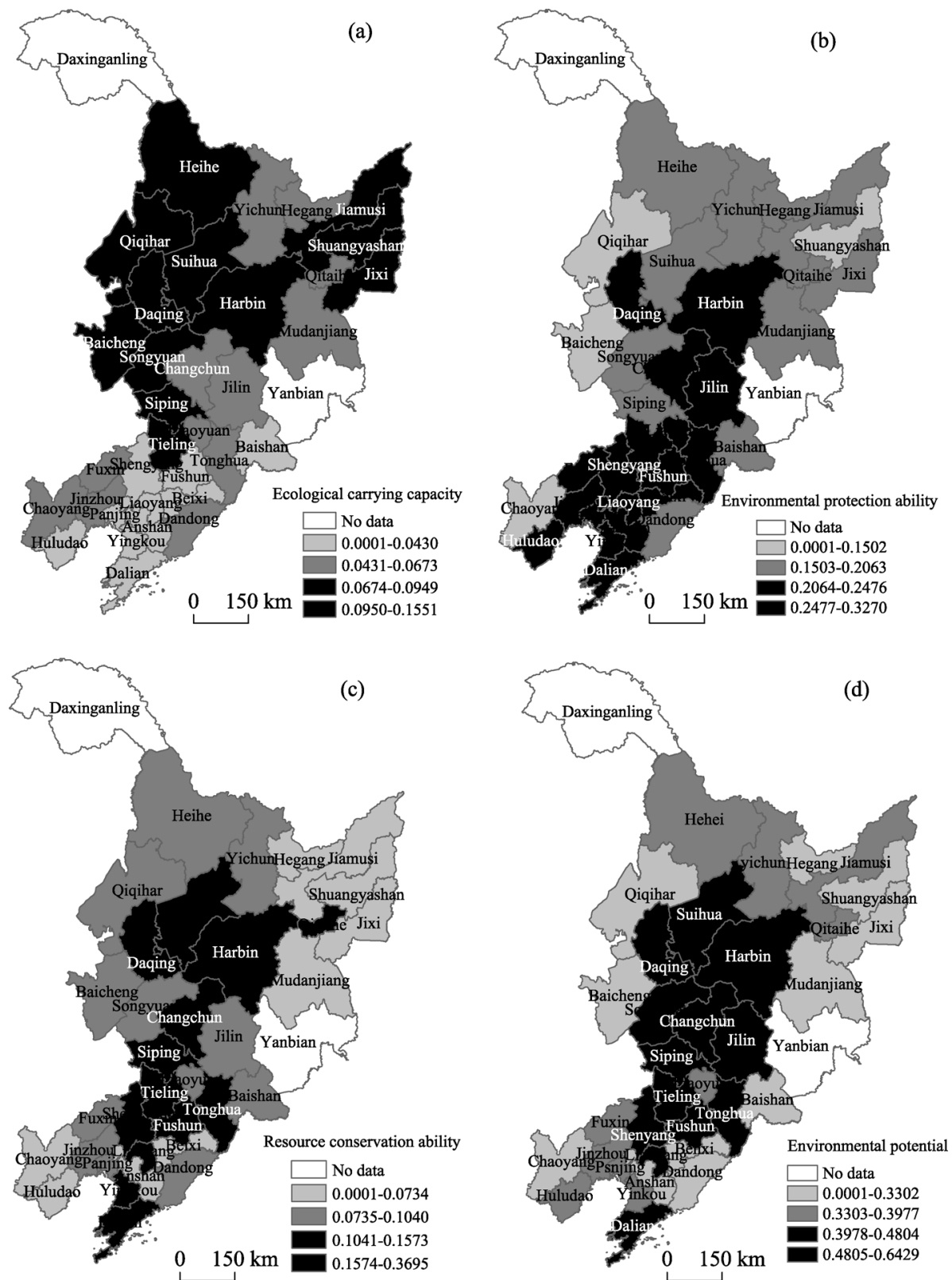

Figure 6 Environmental potential of sustainable urbanization in Northeast China 
Dalian (0.5087), respectively. Qiqihar, Hegang, Baicheng and Chaoyang are the bottom four cities. The highest value of Tonghua is 2.7 times of the minimum value. Results of the components index show that high score ecological carrying capacity cities are concentrated in the western Songnen and Sanjiang plains. As the national environmental protection model cities in China, Dalian, Fushun, Daqing, and Shenyang have high environmental protection ability. These cities have a strong pollutant treatment capability and greening capability, and they do pretty good in executing environmental requirements. Tonghua, Changchun, Tieling, Fushun and Daqing obtained a high score in resource conservation ability. Especially Tonghua was selected as the first batch of the cities "National low-carbon homeland experimental zone" in China. The city has implemented a number of resource-saving and recycling economy projects. In 2010, output value of waste recycling reached 1.66 billion RMB yuan in Tonghua. Figure 7 describes the proportion of components index in prefecture-level cities. Environmental protection ability is the main contributor of the environmental potential. Liaoning and Jilin were mainly affected by resource conservation ability and Heilongjiang Province was mainly affected by ecological carrying capacity and resource conservation ability.

Sustainable urbanization requires that regional development cannot exceed the regional ecological carrying capacity, resources are scientifically used and conserved, energy consumption and waste generated per unit of output is reduced, and waste generated is disposed or recycled of in way which does not pollute the environment (Grimm et al., 2008). Ecological environment of Northeast China is relatively good, except some central and coastal areas. Priority actions for environmental sustainability in this region are development of low-carbon economy or ecological economy, construction adequate environmental infrastructures and improvement of people's living standards.

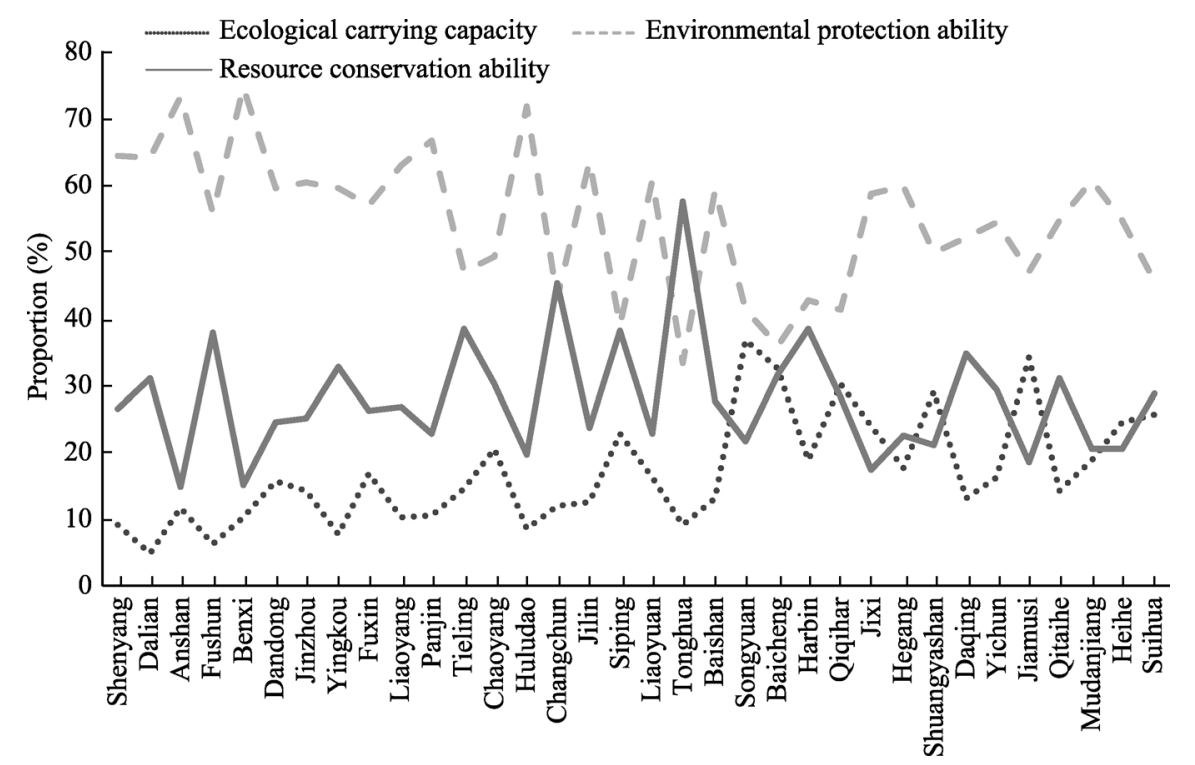

Figure 7 Proportion of components index in environmental potential of sustainable urbanization in Northeast China

\subsection{Spatial variation of comprehensive sustainable urbanization potential}

Figure 8 shows the sustainable urbanization potential scores of 36 prefecture-level cities. 


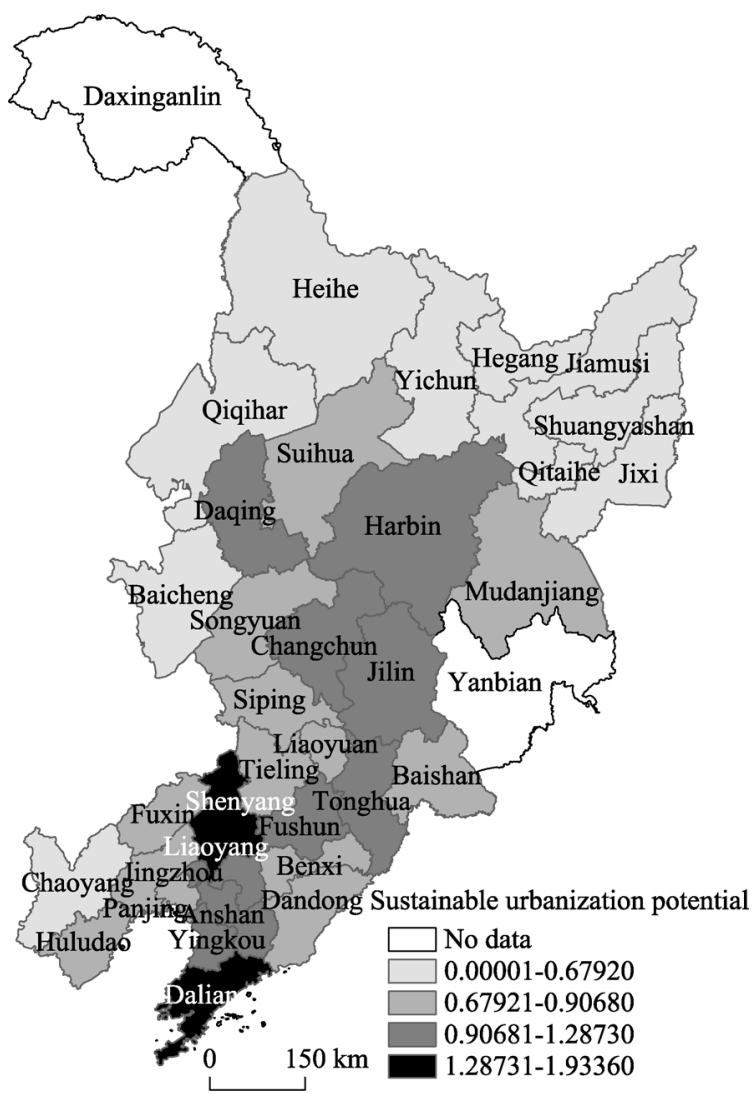

Figure 8 Sustainable urbanization potential of Northeast China
Dalian, Shenyang, Daqing, Changchun and Harbin are the top 4 cities in Northeast China (Figure 8). Except Daqing, most of them are provincial-level cities. Generally, they are large cities with a population of over 1 million. They had a high GDP growth rate, high GDP output, high foreign investment, a high percentage of the population with higher education and high removal efficiency of main pollutants. Chaoyang, Jixi, Qitaihe, Baicheng, Yichun and Hegang are the bottom 6 cities. The bottom cities have much weaker potential than those of the top. In general, these bottom-ranked prefecture-level cities suffer from poor performance in each subsystem of sustainable urbanization potential. Compared with their unsatisfactory economic and social potentials, their environmental potential tends to be higher. According to the differences in the average score, cities in Northeast China are divided into four levels (Table 2). The number of the third and fourth level cities is 11 and 10, respectively, while the number of the first and second level cities is 6 and 7, respectively. Overall, potential of sustainable urbanization in most cities are not high. From the spatial distribution, the higher potential cities are mainly distributed along the Harbin-Dalian railway. These cities have good geographic conditions, better economic development and higher investment in environmental protection (Figure 8). Proportion of system index of sustainable urbanization potential indicates that besides Shenyang, Dalian and a few other cities, environmental potential is the main contributor to sustainable urbanization potential.

Table 2 Statistics of sustainable urbanization potential scores of Northeast China

\begin{tabular}{lccccc}
\hline \multicolumn{1}{c}{ Province } & First level & Second level & Third level & Fourth level & Total \\
\hline Liaoning & 2 & 6 & 5 & 1 & 14 \\
Jilin & 2 & 1 & 4 & 1 & 8 \\
Heilongjiang & 2 & 0 & 11 & 8 & 12 \\
Total & 6 & 7 & 10 & 34 \\
\hline
\end{tabular}

\subsection{Relationships of sustainable urbanization potential value and city size, urbaniza-} tion rate

In this paper, firstly, we take the population in municipal districts (districts under the juris- 
diction of municipality) as a proxy of the city size to study the relationship of sustainable urbanization potential value and the city size. We found that there is no absolute relationship between city size and potential value, large city does not always mean greater potential. Such as Daqing and Tonghua, where population in municipal districts is smaller than Qiqihar and Fushun, but their potential values are higher than these two cities (Figure 9). According to the city size, cities are divided into five grades: mega-cities ( $>2$ million), large cities (1-2 million), big

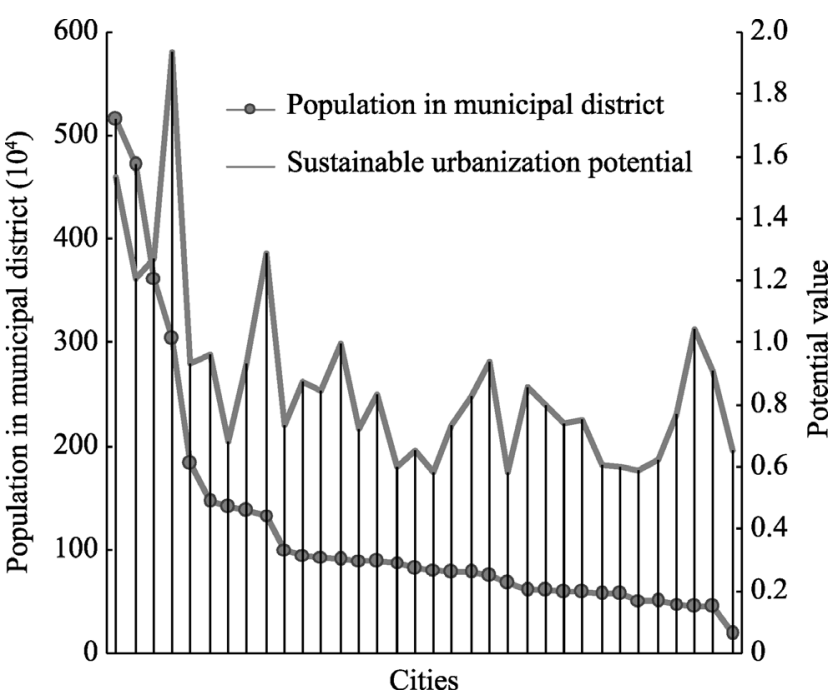

Figure 9 Relationship between sustainable urbanization potential and city size cities $(0.5-1$ million), medium cities $(0.20-0.5$ million) and small cities $(<0.2)$. Next, we calculated the average potential value of each grade. The average potential value of mega-cities is 1.486 , which is significantly bigger $(\mathrm{P}<0.001)$ than the large $(0.959)$, big (0.737), medium (0.906) and small cities $(0.655)$. The average potential value in medium cities is bigger than the big cities $(\mathrm{P}=0.13)$. Secondly, we use the proportion of non-agricultural population as the urbanization rate to study the interrelationship between urbanization rate and sustainable urbanization potential value (Figure 10). A linear regression was used to calculate the correlation coefficient between urbanization rate and sustainable urbanization potential. The value of the correlation coefficient is only 0.012 $\left(y=0.00023 x+0.8587, R^{2}=0.0001, P=0.946\right)$. This result indicates that there is no interrelationship between urbanization rate and sustainable urbanization potential, higher urbanization rate does not lead to higher sustainable urbanization potential in Northeast China, and unilateral pursue urbanization rate cannot improve the potential of sustainable urbanization.

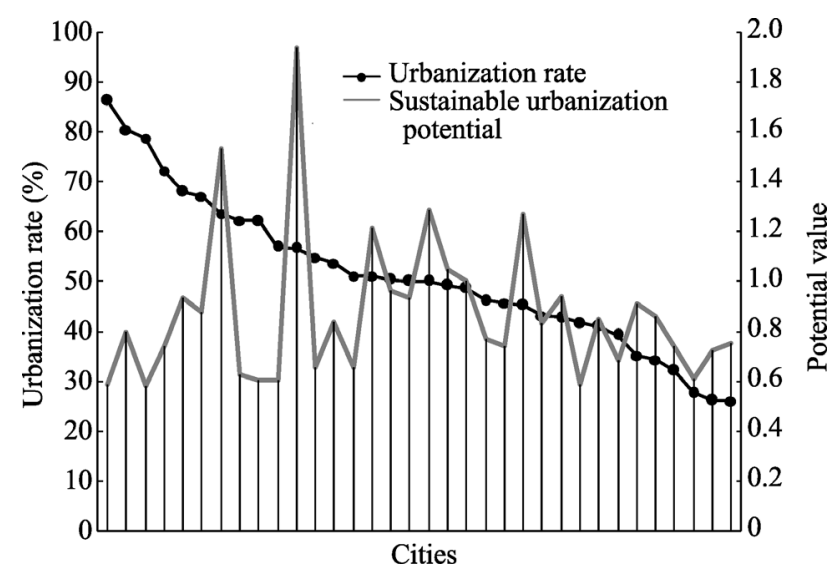

Figure 10 Correlation between sustainable urbanization potential and urbanization rate
As UN Habitat / DFID (2002) denoted population urbanization is not the ultimate goal of sustainable urbanization.

It is well-known that urbanization can produce scale effect, and it can promote the development of economy. However, scale of the city is not the bigger the better. Overall development level of a city not only depends on the size, but also the development of the individual units (Bloom et al., 2008). Blindly pursuing large scale, resulting in agri- 
culture increasingly vulnerable and city presents a false prosperity. Growing gaps between urban and rural areas will lose control. Traffic congestion and environmental pollution will become chronic disease of big city. Focus on developing medium cities and small towns will become a reliable choice of Northeast China. Meanwhile, population urbanization is only one aspect of urbanization. More attention should pay to farmers living in cities, including employment, education, housing, health and so on. Let them enjoy the same rights as urban residents.

\section{Conclusions}

Sustainable urbanization potential is the capability of a region's development in a sustainable urbanization way in future. To reach sustainable urbanization, it is important to evaluate the sustainable urbanization potential of a region, and the results will be very helpful for policy makers to develop scientific measurements. In this paper, we construct an index system with 53 indicators to evaluate the sustainable urbanization potential of Northeast China based on the entropy method. The following conclusions are drawn.

(1) Potential value of sustainable urbanization varies among different cities. Dalian (1.934), Shenyang (1.532), Daqing (1.287), Changchun (1.270) and Harbin (1.209) are the top 4 cities in Northeast China. Potential values in most cities are not high, average potential value is only 0.8706 , and 21 of the cities are located in the third and fourth levels. Higher potential cities are mainly distributed in the central part of Northeast China. These cities own good geographic conditions, better economic development and high investment in environmental protection. For most cities, environmental potential is the main contributor to sustainable urbanization potential.

(2) There is no absolute interrelationship between city size and potential value, large city does not always mean greater potential. The average potential value of mega-cities is 1.486 , which is significantly bigger $(P<0.001)$ than the large $(0.959)$, big $(0.737)$, medium $(0.906)$ and small cities (0.655).

(3) The correlation coefficient between urbanization rate and sustainable urbanization potential is only $0.012\left(\mathrm{R}^{2}=0.0001, \mathrm{P}=0.946\right)$. This result shows that urbanization rate cannot reflect the sustainable urbanization potential of a region. Population urbanization is not the ultimate goal of sustainable urbanization. Cities with high potential of sustainable urbanization still have many shortages and need to be further improved.

This paper provides a comprehensive overview of the strengths and weakness of cities in promoting sustainable urbanization. Since various practices of urbanization exist owing to different backgrounds, the proposed framework also can be applied to various urbanization processes. Entropy method is a widely used approach and objectively determines the weights of the criteria. However, this method also has shortcomings when calculate value centralized samples. Consequently, integrated methodology or new models for measuring the sustainable urbanization potential are necessary in the future study.

\section{Appendix list of all indicators and weights}


$\mathrm{S}_{1}$ GDP growth rate $(0.015)$

$\mathrm{S}_{2}$ Growth rate of investment on fixed assets $(0.017)$

$\mathrm{S}_{3}$ Growth rate of total retail sales of consumer goods $(0.015)$

$\mathrm{S}_{4}$ Proportion of light industrial output value accounting for industrial output value $(0.029)$

Elements gathering capability (E2)

$\mathrm{S}_{5}$ Urban population increment $(0.068)$

$\mathrm{S}_{6}$ Foreign investment growth amount $(0.107)$

$\mathrm{S}_{7}$ Per capita savings $(0.045)$

Global capability (E3)

$\mathrm{S}_{8}$ Total export-import volume (0.133)

$\mathrm{S}_{9}$ Proportion of foreign investment accounting for GDP(0.049)

$\mathrm{S}_{10}$ International tourist arrivals (0.079)

Innovation capability (E4)

$\mathrm{S}_{11}$ Number of R \& D personnel (0.101)

$\mathrm{S}_{12}$ Expenditure on R \& D (0.108)

Rural development capability $\left(\mathrm{S}_{\mathrm{E} 2}\right)$

Agricultural modernization level (E5)

$\mathrm{S}_{13}$ Agricultural mechanization level (0.027)

$\mathrm{S}_{14}$ Agricultural labor productivity (0.046)

$\mathrm{S}_{15}$ Agricultural land productivity (0.032)

Rural industrialization level (E6)

$\mathrm{S}_{16}$ Number of industrial enterprises above designated size in rural areas (0.046)

$\mathrm{S}_{17}$ Gross industrial output value of industrial enterprises above designated size in rural areas $(0.024)$

$\mathrm{S}_{18}$ Rural industrial labor force accounting for the proportion of rural labor force $(0.017)$

Balance ability $\left(\mathbf{S}_{\mathrm{E} 3}\right)$

Fiscal balance (E7)

$\mathrm{S}_{19}$ Per capita expenditure in municipal district / per capita expenditure in non-municipal district $(0.008)$

$\mathrm{S}_{20}$ Expenditure in municipal district / expenditure in non-municipal district $(0.005)$

Investment balance $(\mathrm{E} 8)$

$\mathrm{S}_{21}$ Fixed asset investment of municipal district/fixed asset investment of non-municipal district (0.012)

$\mathrm{S}_{22}$ Per capita fixed assets investment in municipal district / per capita fixed assets investment in non-municipal district (0.007)

Urban-rural integration level (E9)

$\mathrm{S}_{23}$ Per capita GDP in municipal district/per capita GDP in non-municipal district (0.003)

$\mathrm{S}_{24}$ Annual per capita disposable income of urban households / annual per capitanet income of rural households (0.007)

Social potential $\left(\mathbf{S}_{\mathrm{S}}\right)$

Government's social security ability $\left(\mathrm{S}_{\mathrm{S} 1}\right)$

Financial security $(S 1)$

$\mathrm{S}_{25}$ Education expenditure share in total fiscal expenditure (0.022)

$\mathrm{S}_{26}$ Social security and employment expenditure share in total fiscal expenditure (0.053)

$\mathrm{S}_{27}$ Health expenditure share in total fiscal expenditure (0.045)

Personal security $(S 2)$

$\mathrm{S}_{28}$ Urban unemployment rate (0.048)

$\mathrm{S}_{29}$ Proportion of the population under the minimum living guarantee line (0.013)

Public infrastructure supply ability $\left(\mathbf{S}_{\mathbf{S} 2}\right)$

Medical services supply (S3)

$\mathrm{S}_{30}$ Number of doctors in health institutions per 10000 population $(0.064)$

$\mathrm{S}_{31}$ Number of beds in health institutions per 10000 population (0.030)

Transportation supply capability (S4)

$\mathrm{S}_{32}$ Number of buses per 10000 population (0.060)

$\mathrm{S}_{33}$ Total freight volume $(0.095)$ 
$\mathrm{S}_{34}$ Passenger volume (0.094)

Water and electricity supply capability (S5)

$\mathrm{S}_{35}$ Per capita water supply in municipal district (0.094)

$\mathrm{S}_{36}$ Per capita electricity consumption (0.055)

Culture and technology support ability $\left(\mathrm{S}_{\mathrm{S} 3}\right)$

\section{Technology supportive (S6)}

$\mathrm{S}_{37}$ Proportion of population engaged in research, technical services and geological prospecting $(0.081)$

$\mathrm{S}_{38}$ Proportion of science and technology expenditure to total fiscal expenditure (0.081)

Culture supportive (S7)

$\mathrm{S}_{39}$ Proportion of culture media expenditure to total fiscal expenditure (0.024)

$\mathrm{S}_{40}$ Number of public library books per 100 population $(0.141)$

Environmental potential $\left(S_{E n}\right)$

Ecological carrying capacity $\left(\mathbf{S}_{\mathrm{En} 1}\right)$

Water resources carrying capacity (N1)

$\mathrm{S}_{41}$ Water resources carrying capacity index (0.041)

Land carrying capacity (N2)

$\mathrm{S}_{42}$ Arable land relative carrying capacity (0.142)

Resource conservation ability $\left(\mathbf{S}_{\mathrm{En} 2}\right)$

Resource efficient use capability (N3)

$\mathrm{S}_{43}$ Energy consumption per unit of output (0.037)

$\mathrm{S}_{44}$ Water consumption per unit of output $(0.015)$

Waste utilization capability (N4)

$\mathrm{S}_{45}$ Output value of waste recycling (0.300)

$\mathrm{S}_{46}$ Comprehensive utilization rate of industrial solid waste (0.040)

Environmental protection ability $\left(\mathbf{S}_{\mathrm{En} 3}\right)$

Greening capability (N5)

$\mathrm{S}_{47}$ Per capita public green area (0.103)

$\mathrm{S}_{48}$ Percentage of greenery coverage $(0.028)$

Waste treatment capability (No)

$\mathrm{S}_{49}$ Percentage of industrial sewage discharged meeting national standard (0.049)

$\mathrm{S}_{50}$ Industrial sulfur dioxide removal rate (0.109)

$\mathrm{S}_{51}$ Industrial dust removal rate $(0.039)$

$\mathrm{S}_{52}$ Urban sewage treatment rate (0.055)

$\mathrm{S}_{53}$ Garbage treatment rate $(0.042)$

\section{References}

Arrow K J, 1962. The economic implications of learning by doing. The Review of Economic Studies, 29(3): $155-173$.

Bloom D E, Canning D, Fink G, 2008. Urbanization and the wealth of nations. Science, 319: 772-775.

Chen M X, Lu D D, Zha L S, 2010. The comprehensive evaluation of China's urbanization and effects on resources and environment. Journal of Geographical Sciences, 20(1): 17-30.

Chen M X, Tang Z P, Bai Y P et al., 2015. Relational pattern of urbanization and economic developmen: Parameter re-evaluation of the Chenery model. Journal of Geographical Sciences, 25(8): 991-1002.

Dewan A M, Yamaguchi Y, 2009. Land use and land cover change in Greater Dhaka, Bangladesh: Using remote sensing to promote sustainable urbanization. Applied Geography, 29(3): 390-401.

Ding S B, 2005. Investigation and analysis on the problem of poverty in resource based cities, Northeast China. Opening Herald, (6): 28-32. (in Chinese)

Drakakis-Smith D, Dixon C, 1997. Sustainable uribanization in Vietnam. Geoforum, 28(1): 21-38.

Enserink B, Koppenjan J, 2007. Public participation in China: Sustainable urbanization and governance. Management of Environmental Quality, 18(4): 459-474.

Fang C L, Wang J, 2013. A theoretical analysis of interactive coercing effects between urbanization and eco-environment. Chinese Geographical Science, 23(2): 147-162.

Florida R, 1995. Toward the learning region. Futures, 27(5): 527-536.

Gan J, Guo F Y, Chen C et al., 2015. The spatio-temporal evolution characteristics of urbanization spatial 
differentiation in Northeast China. Scientia Geographica Sinica, 35(5): 565-574. (in Chinese)

Grimm N B, Faeth S H, Golubiewski N E et al., 2008. Global change and the ecology of cities. Science, 319 : 756-760.

He X G, 1992. Urbanization potential classification of Chinese cities. Population Journal, (6): 7-12. (in Chinese)

Holden E, 2004. Ecological footprints and sustainable form. Journal of Housing and the Built Environment, 19(1): 91-209.

Irwin E G, Jayaprakash C, Munroe D K, 2009. Towards a comprehensive framework for modeling urban spatial dynamics. Landscape Ecology, 24(9): 1223-1236.

Jantz C A, Goetz S J, Shelley M K, 2003. Using the SLEUTH urban growth model to simulate the impacts of future policy scenarios on urban land use in the Baltimore-Washington metropolitan area. Environment and Planning B: Planning and Design, 30: 251-271.

Li N, Ding S B, Wang S J et al., 2010. Study on improvement of labors' employment of low urbanization cities in the Northeast Area. China Population, Resources and Environment, 20(5): 129-133. (in Chinese)

Liang Z M, Chen C, Liu J S et al., 2013. Tiers features and comprehensive measures of urbanization development quality of Northeast China. Scientia Geographica Sinica, 33(8): 926-934. (in Chinese)

Liu H N, Sun Z L, 2007. Cluster analysis of rural urbanization development potential in Heilongjiang province. China Forestry Economy, (3): 33-35. (in Chinese)

Liu S W, 2014. Sustainable urbanization in Northeast China: Regional potential and strategical choice of sustainable development path [D]. Beijing: University of Chinese Academy of Sciences.

Lu D D, 2003. Theory and Practice of Regional Development in China. Beijing: Science Press. (in Chinese)

Ma R F, Wang X C, Shen Y F et al., 2009. Regional development potential theory: Status and prospects. Science and Technology Management Research, (11): 118-130.

Meine P V D, Zhang M S, 2005. Sustainability indices as a tool for urban managers, evidence from four medium-sized Chinese cities. Environmental Impact Assessment Review, 25: 667-688.

Niu W Y, 2009. Essential points of strategic design of Chinese new-approach urbanization. Bulletin of Chinese Academy of Sciences, 24(2): 130-137. (in Chinese)

Niu W Y, 2012. China New Urbanization Report 2012. Beijing: Science Press. (in Chinese)

Pivo G, 1996. Toward sustainable urbanization on Mainstreet Cascadia. Cities, 13(5): 339-354.

Romer P M, 1990. Endogenous technological change. Journal of Political Economy, 98(5): 71-102.

Roy M, 2009. Planning for sustainable urbanization in fast growing cities: Mitigation and adaptation issues addressed in Dhaka, Bangladesh. Habitat International, 33(3): 276-286.

Shen L Y, Peng Y, Zhang X L et al., 2012. An alternative model for evaluating sustainable urbanization. Cities, 29: 32-39.

Shen L Y, Zhou J Y, 2014. Examining the effectiveness of indicators for guiding sustainable urbanization in China. Habitat International, 44: 111-120.

Shen L Y, Zhou J Y, Skitmore M et al., 2015. Application of a hybrid entropy-McKinsey matrix method in evaluating sustainable urbanization: A China case study. Cities, 42: 186-194.

Sun P J, Feng X P, Sun H et al., 2013. Comparative analysis of characteristics, effects and driving factors of urban sprawl in Changchun-Jilin during 2000-2009. Progress in Geography, 32(3): 382-388. (in Chinese)

United Nations Human Settlement Programme/Department for International Development (UN-Habitat/DFID), 2002. Sustainable urbanisation: Achieving agenda 21. UN-Habitat/DFID, Nairobi.

United Nations, 2012. World Urbanization Prospects. The 2011 version. New York, USA: United Nations.

Verma A, Sudhira H S, Rathi S et al., 2013. Sustainable urbanization using high speed rail (HSR) in Karnataka, India. Research in Transportation Economics, 38: 67-77.

Wang S J, Song Y, Feng Z X et al., 2011. Pattern and progress of large urban agglomerations and urban flows intensity in Northeast China. Scientia Geographica Sinica, 31(3): 287-294. (in Chinese)

Wang S J, Wan D, Song Y, 2008. Structural and functional optimization of urban agglomerations in the Northeast old industrial Base of China. Scientia Geographica Sinica, 28(1): 16-20. (in Chinese)

Yi P, Liu J S, Chen C, 2015. The coordination development of four moderations in Jilin province since the revival of Northeast China. Scientia Geographica Sinica, 35(9): 1101-1108. (in Chinese)

Zang R, Zhang P, Yang Q S et al., 2013. Comprehensive measure and spatial-temporal evolotion of urbanization level in Jilin province. Scientia Geographica Sinica, 33(10): 1231-1237. (in Chinese)

Zhang P Y, 2013. Urbanization progress, problem and policy in Northeast China since 2003. Bulletin of Chinese Academy of Sciences, 28(1): 39-45. (in Chinese)

Zhang X L, 2015. Sustainable urbanization: A bi-dimensional matrix model. Journal of Cleaner Production. doi:10.1016/j.jclepro.2015.08.036.

Zhu F F, 2014. Evaluation on the development level of new urbanization in Heilongjiang province [D]. Harbin: Harbin University of Science and Technology. (in Chinese)

Zhu J M, Simarmata H A, 2015. Formal land rights versus informal land rights: Governance for sustainable urbanization in the Jakarta metropolitan region, Indonesia. Land Use Policy, 43: 63-73. 